\title{
Coping with the Crisis: People with Severe Mental Disorders Acting for Social Change Through Sustainable Energy
}

\author{
Carta $\mathrm{MG}^{1,{ }^{*}}$, Sancassiani $\mathrm{F}^{1}$, Lecca $\mathrm{ME}^{1}$, Pintus $\mathrm{E}^{1}$, Pintus $\mathrm{M}^{1}$, Pisano $\mathrm{E}^{1}$, Moro $\mathrm{MF}^{1}$ and Anger- \\ meyer $\mathrm{CM}^{2}$
}

\author{
${ }^{I}$ Department of Public Health, Clinical and Molecular Medicine - University of Cagliari (Italy) \\ ${ }^{2}$ Center for Public Mental Health, Gosing and Wagram, Vienna, Austria
}

\begin{abstract}
Background: The aim of the study was to examine the efficacy of a vocational training program on renewable energy sources in reducing disabilities of people with chronic psychosis (CP). The innovative element was that the project could produce major advantages regarding the economic needs of the whole area involved.

Methods: Experimental Cohort, 26 subjects with CP (EC); Control Cohort1, 130 subjects with CP following pharmacotherapy plus other rehabilitation activities (CIC); Control Cohort2, 101 subjects with CP following the usual treatment (pharmacotherapy) (CUC). Study tool: Health of the Nation Outcome Scales (HoNOS). Assessment made at the start of the study (T0) and after three months (T1). Statistical analysis made by MANOVA.

Results: Improvement in HoNOS total score in both groups $(\mathrm{F}=7.574, \mathrm{p}=0.000)$ with non-significant differences between groups over time $(\mathrm{F}=1.336, \mathrm{p}=0.252)$ was found comparing $\mathrm{EC}$ vs. CIC. Greater improvement in EC vs. CIC was shown in the HoNOS "impairment" scale $(\mathrm{F}=4.910, \mathrm{p}=0.028)$. EC vs. CUC: both groups improved in HoNOS total score $(\mathrm{F}=9.440, \mathrm{p}=0.000)$ but the improvement was greater in $\mathrm{EC}(\mathrm{F}=2.273, \mathrm{P}=0.048)$.

Conclusions: Work inclusion, as well as other rehabilitation treatments, reduces the social needs of people with chronic psychosis. Work inclusion in a project with real relevance for the area where these people live, produces more improvement of cognitive, physical and somatic disabilities, probably related to a better outcome in self-efficacy.
\end{abstract}

Keywords: Chronic psychosis, work inclusion, follow-up, rehabilitation, Crisis, HoNOS.

\section{INTRODUCTION}

Work inclusion is a common practice in the rehabilitation and treatment of people with severe mental disorders [1]. Having a job can stimulate skills, motivate a personal project, provide economic independence and can fight stigma through the recognition of a social role. However given our very competitive market and the current economic crisis in Europe - which is particularly felt in the South of Italy, Sardinia included - finding a job for people with disabilities is very difficult at a time when many people with abilities and high job competences are unemployed [2].

The project "A thousand photovoltaic roofs" overturned this critical situation by trying to generate opportunities. The strategy was to put into place a project providing work for people with severe mental disorders right at the heart of the needs of a territory. The project was planned to generate jobs for users with severe mental disorders, and also to produce innovative answers to the profound needs of the territory.

*Address correspondence to this author at the Department of Public Health, Clinical and Molecular Medicine, Cittadella Universitaria di Monserrato, 09042 Monserrato (Cagliari), Italy; Tel: +39 335499994;

Fax:+39070 6093498; E-mail: mgcarta@tiscali.it
The rural economy of southern Sardinia is based on a wealth of small family-run agricultural farms, to which the EU energy policies are a real problem because they do not have the technical expertise and funds to comply with the new standards on energy consumption and energy saving.

Our group has developed a project funded by the European Social Fund with the aim of training young people with pathways of deviance, personality disorders and school dropout, and issue to them the title of "photovoltaics engineer". A parallel project, also funded by the European Social Fund, has created a social enterprise that operates in the installation of renewable energy systems. This social enterprise has employed some of the technicians trained under the first project, and has trained some people with severe mental disorders to become workers in the renewable energy industry. The secondary objective of this project was to offer farmers in the area the possibility to produce energy from renewable sources at low design and installation costs. This action of social inclusion would create a sustainable context for future employment and act strongly against stigma, because the project would solve a major problem for farmers.

The projects were led by the University of Cagliari in collaboration with the public mental health centres and the municipalities of the areas concerned, as well as with the organizations representing the small agricultural enterprises 
in the area. This extensive involvement was made possible thanks to the relevance of the project objectives for the economy of the affected areas.

The goal of our work is to measure the outcomes in terms of disability and well-being of the people with severe mental disorders who benefited from this training and work project, and to see whether this innovative strategy has produced better outcomes than the "traditional" rehabilitation activities that are provided in the same region by public mental health services.

\section{METHODS}

\section{Design}

Controlled cohort study of patients diagnosed with schizophrenic disorder, schizoaffective disorder, bipolar affective disorder with psychotic symptoms (ICD-X).

\section{Sample}

- Experimental Cohort (EC): 26 subjects involved in a three-month intervention with training as "worker in the renewable energy business".

- Control Cohort 1 (CIC): 130 subjects followed the usual integrated treatment (pharmacotherapy plus other rehabilitation activities).

- Control Cohort 2 (CUC): 101 subjects followed the usual treatment (pharmacotherapy) T0).

(See Table 1 for age, gender and HoNOS total score at

\section{Selection of the Sample}

Patients came from the catchment areas that participated in the study on the quality assessment of the mental health care services in Sardinia [3].

In the 16 territorial centers for psychiatric care (CSMs or "Centri di Salute Mentale") participating in the research a total sample of 259 people with schizophrenic or affective psychosis was selected. Only two CSMs had the opportunity to lead the project "A thousand photovoltaic roofs", thus the Experimental Cohort consisted of 26 patients from one of the 8 CSMs of the Cagliari County ("Provincia") and from one of the two CSMs of the Iglesias County selected for rehabilitation activities and involved in this project.

The Control Cohort 1 consisted of 130 subjects from the remaining 14 CSMs participating in the above-mentioned research (Carta et al. 2013), selected for rehabilitation activities and involved in rehabilitation and work education activities, such as art therapy, sailing therapy, trekking and socialization groups, at the time when the project was carried out.

The Control Cohort 2 consisted of 101 subjects from the other 14 CSMs participating in the above-mentioned research (Carta et al. 2013) who had not been selected or refused to participate in rehabilitation activities or psychotherapy at the time of project implementation.

\section{Instruments}

Health and social functioning outcomes were measured by the Health of the Nation Outcome Scale (HoNOS) [4].
The Royal College of Psychiatrists' Research Unit (CRU) developed this 12-item instrument to measure the health and social functioning of people with severe mental illness. The scales can be completed after routine clinical assessment in any setting and have a variety of uses for clinicians, researchers, and administrators and, in particular, for health care officers and providers (Royal College of Psychiatrists, 2011). HoNOS is the most widely used clinical outcome measure by the mental health services of England [5]. The HoNOS measures patient outcomes in four main domains: behavior (3 items), cognitive and physical impairment ( 2 items), symptoms (3 items), and social functioning (4 items). Each item is scored from 0 to 4 , ranging from $0=$ "no problem" to $4=$ "severe/very severe problem". Higher scores indicate a worse outcome.

\section{Assessment}

Assessment was made at the start of rehabilitation activities (T0) and three months later (T1).

\section{Statistical Analysis}

To examine the homogeneity of EC and of the two Control Cohorts concerning age, gender and HoNOS total score at T0 we conducted $\chi^{2}$ test for categorical variable (gender) and a series of one way ANOVAs for continuous variables (age; HoNOS total score).

To test differences in the improvement of the cohorts on HoNOS total scores, as well as on its four main domains (behaviour; cognitive and physical impairment; symptoms; social functioning), we conducted a multivariate analysis of variance (MANOVA), with "Cohorts" as the betweensubjects factor.

\section{Ethical Aspects}

Each subject in the study was identified with a code number that researchers could not link to their name. Informed consent for the use of anonymous data for scientific purposes was obtained from each patient. This study was approved by the Ethics Committee of the Cagliari University Hospital "Azienda Mista Ospedaliero Universitaria di Cagliari”.

\section{RESULTS}

As shown in Table 1, EC and the control cohorts (CIC and CUC) were homogeneous for gender, age and HoNOS scores at T0. EC vs. CIC: gender $\chi^{2}=0.062, p=0.98,1 \mathrm{df}$; age $\mathrm{F}=1.546 ; \mathrm{p}=0.216$, df $1,154,155 ;$ HoNOS total score $\mathrm{F}=0.047, \mathrm{p}=0.828, \mathrm{df1}, 154,155$; behaviour $\mathrm{F}=0.264$, $\mathrm{p}=0.608$, df $1,154,155$; impairment $\mathrm{F}=0.080, \mathrm{p}=0.778$, df $1,54,155$; symptoms $\mathrm{F}=0.443, \mathrm{p}=0.507$, df $1,154,155$; social $\mathrm{F}=0.070, \mathrm{p}=0.792$, df $1,154,55)$, (EC vs CUC: $\chi^{2}=0.581$, $\mathrm{p}=0.446$, 1df); age $\mathrm{F}=0.438 ; \mathrm{p}=0.509$, df $1,125,126$; HoNOS total score $\mathrm{F}=0.032, \mathrm{p}=0.859$, $\mathrm{df1}, 125,126$; behaviour $\mathrm{F}=0.336, \mathrm{p}=0.563$, df $1,125,126$; impairment $\mathrm{F}=0.044$, $\mathrm{p}=0.834$, df $1,25,126$; symptoms $\mathrm{F}=4.050, \mathrm{p}=0.046$, df $1,125,126$; social $\mathrm{F}=0.504, \mathrm{p}=0.479$, df 1,125,126.

Table 2 reports means and standard deviations of the HoNOS scores (total and in each domain) at T0 and T1 for EC and CIC. Both cohorts showed significant improvement 
Table 1. Characteristics and Homogeneity of the Cohorts

\begin{tabular}{|c|c|c|c|c|c|c|c|c|}
\hline Cohorts & $\mathbf{N}$ & $\begin{array}{c}\text { GENDER } \\
\text { Frequence } \\
(\%)\end{array}$ & $\begin{array}{c}\text { AGE } \\
\text { Mean (sd) }\end{array}$ & \multicolumn{5}{|c|}{$\begin{array}{c}\text { HoNOS Scores at T0 } \\
\text { Mean (sd) }\end{array}$} \\
\hline $\mathrm{EC}$ & 26 & $\begin{array}{c}\text { female }=6 \\
(23.1 \%) \\
\text { male }=20 \\
(76.9 \%)\end{array}$ & $\begin{array}{c}43.54 \\
(8.411)\end{array}$ & $\begin{array}{c}16.08 \\
(6.609)\end{array}$ & $\begin{array}{c}2.31 \\
(1.806)\end{array}$ & $\begin{array}{c}2.46 \\
(1.581)\end{array}$ & $\begin{array}{c}3.73 \\
(2.070)\end{array}$ & $\begin{array}{c}7.73 \\
(3.269)\end{array}$ \\
\hline $\mathrm{CIC}$ & 130 & $\begin{array}{c}\text { female }=33 \\
(25.4 \%) \\
\text { Male }=97 \\
(74.6 \%)\end{array}$ & $\begin{array}{c}46.76 \\
(11.674)\end{array}$ & $\begin{array}{c}16.44 \\
(7.944)\end{array}$ & $\begin{array}{c}2.06 \\
(2.302)\end{array}$ & $\begin{array}{c}2.35 \\
(1.956)\end{array}$ & $\begin{array}{c}4.06 \\
(2.358)\end{array}$ & $\begin{array}{c}7.97 \\
(4.360)\end{array}$ \\
\hline CUC & 101 & $\begin{array}{c}\text { Female }=31 \\
(30.7 \%) \\
\text { Male }=70 \\
(69.3 \%)\end{array}$ & $\begin{array}{c}45.38 \\
(13.480)\end{array}$ & $\begin{array}{c}16.43 \\
(9.425)\end{array}$ & $\begin{array}{c}2.04 \\
(2.172)\end{array}$ & $\begin{array}{c}2.37 \\
(2.171)\end{array}$ & $\begin{array}{c}4.96 \\
(2.929)\end{array}$ & $\begin{array}{c}7.07 \\
(4.446)\end{array}$ \\
\hline $\mathrm{EC} v s \mathrm{CUC}$ & 127 & $\begin{array}{c}\chi^{2}=0.581 \\
\mathrm{p}=0.446 \\
\mathrm{df}=1\end{array}$ & $\begin{array}{c}\mathrm{F}=0.438 \\
\mathrm{p}=0.509 \\
\mathrm{df1} 1125 ; 126\end{array}$ & $\begin{array}{c}\mathrm{F}=0.032 \\
\mathrm{p}=0.859 \\
\mathrm{df1} ; 125 ; 126\end{array}$ & $\begin{array}{c}\mathrm{F}=0.336 \\
\mathrm{p}=0.563 \\
\mathrm{df} 1 ; 125 ; 126\end{array}$ & $\begin{array}{c}\mathrm{F}=0.044 \\
\mathrm{p}=0.834 \\
\mathrm{df1} 1125 ; 126\end{array}$ & $\begin{array}{c}\mathrm{F}=4.050 \\
\mathrm{p}=0.046 \\
\mathrm{df1} 1 ; 125 ; 126\end{array}$ & $\begin{array}{c}\mathrm{F}=0.504 \\
\mathrm{p}=0.479 \\
\mathrm{df} 1 ; 125 ; 126\end{array}$ \\
\hline
\end{tabular}

Table 2. Experimental Cohort Versus Control Cohort 1: Means and Standard Deviations for the HoNOS Scores at T0 and T1.

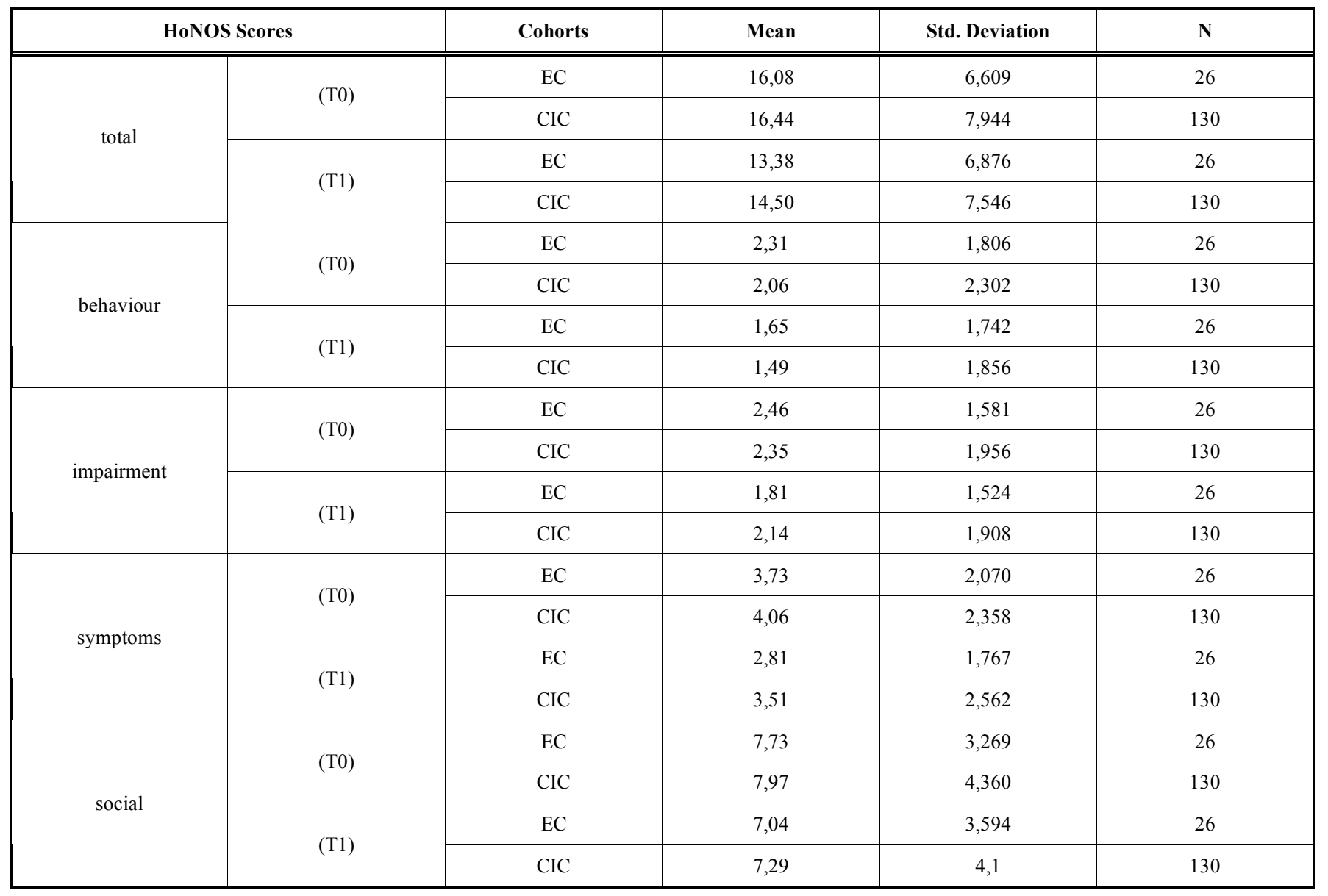


Table 2.a. Experimental Cohort Versus Control Cohort 1: MANOVA Multivariate Test

\begin{tabular}{|c|c|c|c|c|}
\hline & F & Sig. & Hypothesis df & Error df \\
\hline \hline time & 7,574 &, 000 & 5,000 & 150,000 \\
\hline cohorts & 1,239 & 0,294 & 5,000 & 150,000 \\
\hline time X cohorts & 1,336 &, 252 & 5,000 & 150,000 \\
\hline
\end{tabular}

Table 2.b. Experimental Cohort Versus Control Cohort 1: MANOVA Univariate Tests

\begin{tabular}{|c|c|c|c|c|}
\hline & Measure & $\mathbf{F}$ & Sig. & df \\
\hline \multirow{3}{*}{ time } & hon_beh & 13,722 &, 000 & 1,154 \\
\hline & hon_imp & 18,308 &, 000 & 1,154 \\
\hline & hon_sym & 12,951 &, 000 & 1,154 \\
\hline \multirow[t]{4}{*}{ cohorts } & hon_tot & 0,218 & ,641 & 1,154 \\
\hline & hon_beh & 0,251 & ,617 & 1,154 \\
\hline & hon_imp & 0,076 &, 783 & 1,154 \\
\hline & hon_sym & 1,207 &, 274 & 1,154 \\
\hline \multirow{3}{*}{ time $\mathrm{x}$ cohorts } & hon_imp & 4,910 &, 028 & 1,154 \\
\hline & hon_sym &, 809 &, 370 & 1,154 \\
\hline & hon_soc &, 001 & ,969 & 1,154 \\
\hline
\end{tabular}

Table 3. Experimental Cohort Versus Control Cohort 2: Means and Standard Deviations for the HoNOS Scores at T0 and T1.

\begin{tabular}{|c|c|c|c|c|c|}
\hline \multicolumn{2}{|c|}{ HoNOS Scores } & \multirow{2}{*}{$\begin{array}{c}\text { Cohorts } \\
\text { CUC }\end{array}$} & \multirow{2}{*}{$\begin{array}{c}\text { Mean } \\
16,43\end{array}$} & \multirow{2}{*}{$\begin{array}{c}\text { Std. Deviation } \\
9,425\end{array}$} & \multirow{2}{*}{$\frac{\mathbf{N}}{101}$} \\
\hline total & \multirow{2}{*}{ (T0) } & & & & \\
\hline & & GS & 16,08 & 6,609 & 26 \\
\hline & \multirow{2}{*}{ (T1) } & CUC & 14,85 & 8,903 & 101 \\
\hline & & GS & 13,38 & 6,876 & 26 \\
\hline \multirow{2}{*}{ behaviour } & \multirow{2}{*}{ (T1) } & CUC & 1,60 & 2,074 & 101 \\
\hline & & GS & 1,65 & 1,742 & 26 \\
\hline \multirow[t]{2}{*}{ impairment } & \multirow{2}{*}{ (T0) } & CUC & 2,37 & 2,171 & 101 \\
\hline & & GS & 2,46 & 1,581 & 26 \\
\hline \multirow[t]{4}{*}{ symptoms } & \multirow{2}{*}{ (T0) } & CUC & 4,76 & 2,929 & 101 \\
\hline & & GS & 3,73 & 2,070 & 26 \\
\hline & \multirow{2}{*}{ (T1) } & CUC & 4,40 & 2,987 & 101 \\
\hline & & GS & 2,81 & 1,767 & 26 \\
\hline
\end{tabular}


Table 3. contd...

\begin{tabular}{|c|c|c|c|c|c|}
\hline \multicolumn{2}{|c|}{ HoNOS Scores } & Cohorts & Mean & Std. Deviation & $\mathbf{N}$ \\
\hline \multirow[t]{4}{*}{ social } & \multirow{2}{*}{ (T0) } & CUC & 7,07 & 4,446 & 101 \\
\hline & & GS & 7,73 & 3,269 & 26 \\
\hline & (T1) & CUC & 6,67 & 4,018 & 101 \\
\hline & & GS & 7,04 & 3,594 & 26 \\
\hline
\end{tabular}

Table 3.a. Experimental Cohort Versus Control Cohort 2: MANOVA Multivariate Test

\begin{tabular}{|c|c|c|c|}
\hline & F & Sig. & Hypothesis df \\
\hline \hline time & 9,440 &, 000 & 5,000 \\
\hline cohorts & 2.526 & 0.033 & 5,000 \\
\hline time X cohorts & 2.269 &, 052 & 5,000 \\
\hline
\end{tabular}

Table 3.b. Experimental Cohort Versus Control Cohort 2: MANOVA Univariate Tests

\begin{tabular}{|c|c|c|c|c|}
\hline & Measure & $\mathbf{F}$ & Sig & df \\
\hline \multirow[t]{3}{*}{ time } & hon_tot & 32,805 &, 000 & 1,125 \\
\hline & hon_imp & 21,478 &, 000 & 1,125 \\
\hline & hon_sym & 26,150 &, 000 & 1,125 \\
\hline \multirow[t]{3}{*}{ cohorts } & hon_tot & ,232 & ,631 & 1,125 \\
\hline & hon_beh &, 140 &, 709 & 1,125 \\
\hline & hon_imp & ,099 &, 754 & 1,125 \\
\hline \multirow{4}{*}{ time $X$ cohorts } & hon_beh & ,479 & ,490 & 1,125 \\
\hline & hon_imp & 6,571 &, 012 & 1,125 \\
\hline & hon_sym & 1,521 & ,220 & 1,125 \\
\hline & hon_soc & ,645 &, 423 & 1,125 \\
\hline
\end{tabular}

in HoNOS scores (time: $\mathrm{F}=7.574, \mathrm{p}=0.000$ ) but there were no significant differences between cohorts over time (time $\mathrm{x}$ cohorts: $\mathrm{F}=1.336, \mathrm{p}=0.252$ ).

However, MANOVA univariate tests showed that in the Experimental Cohort (EC) there was a significant improvement in the "cognitive and physical impairment" domain of HoNOS (time $x$ cohorts: $F=4.910, p=0.028$ ).

Table 3 shows means and standard deviations of the HoNOS scores (total and in each domain) at T0 and $\mathrm{T} 1$ for EC and CUC. Both groups improved in HoNOS scores $(\mathrm{F}=9.440, \mathrm{p}=0.000)$ but the improvement was greater in $\mathrm{EC}$ (time $\mathrm{x}$ cohorts $\mathrm{F}=2.273, \mathrm{P}=0.048$ ). MANOVA univariate tests showed that in the Experimental Cohort (EC) there was a better outcome in the HoNOS "symptoms" domain at T0 and T1 (cohorts: $F=5,621, p=0.019$ ). Furthermore, in the Experimental Cohort (EC) there was a significant improvement in HoNOS "cognitive and physical impairment" domain (time $x$ cohorts: $F=6.571, p=0.012$ ).

\section{DISCUSSION}

Work inclusion, as well as conventional rehabilitation treatments over a three-month project were shown to reduce the social disabilities related to severe mental illnesses with chronic psychosis. Work inclusion in a project with real 
relevance for the catchment areas where these people live, produces more improvements in cognitive, physical and somatic disabilities than other rehabilitation programs. The same innovative treatment produces an improvement in the total score of the HoNOS scale when compared with a group of patients who take the drug treatment only and does not receive additional rehabilitative interventions.

Recently, new perspectives on the concept of recovery from schizophrenia and other severe mental illnesses have stimulated research, and challenged treatment providers to adopt a more optimistic attitude and collaborative approach in the rehabilitation and treatment of people suffering from severe mental disorders [6-8]. This approach sees recovery more as a personal journey rather than a set outcome, and one that may involve developing hope, a secure base, supportive relationships, empowerment, social inclusion, coping skills, and meaning [9]. The recovery of a durable sense of the self (if this had been broken or destroyed) has been proposed as the main element in this approach [10]. It was suggested that the process of creating a positive sense of the self can be greatly facilitated by experiences of interpersonal acceptance, mutuality, and a sense of social belonging; and it is often challenging in the face of the typical barrier of overt and covert negative messages that come from the broader social context $[11,12]$. The importance of work in this process toward self-esteem has been emphasized in connection with meeting responsibilities, learning how to manage stress, and achieve a socially recognized role [9]. Spanoil et al. identified moving into "roles that are meaningful, productive, and valued in the larger society" as one of the main tasks of recovery [13].

However the job placement and job training that can be offered to people with severe mental disorders do not always have the features of a real job. Very often these kinds of work are out of the market and resemble more a form of financial assistance than a productive activity. This type of work can have little effect on the self-esteem of users.

Also training with no prospects of a true inclusion into work can hardly motivate a user.

A previous study carried out in Albania by our group followed subjects with severe mental disorders in a work training project [1]. The project involved both people discharged from the hospital and living at home, and people still living in the hospital. The training course consisted of two morning sessions per week in a greenhouse owned by the town of Vlore. The project included also educational lessons that took place at a public technical secondary school. Both the home and the hospital groups were shown to improve in the total HoNOS score during the one year follow-up [1]. But notably, the item concerning work skills improved more in the home group than in the hospital group. We believed that one reason could be that the former experienced work training more as a useful thing in view of more realistic chances to find a job, while to the hospitalised people the training may have been more of theoretical interest [1].

Vocational rehabilitation significantly improved also the patients' performance in the cognitive measures that assess execution functions (concept formation, shifting ability, flexibility, inhibitory control, and judgment and criticism skills) [14]. The subjects who received both cognitive remediation and vocational rehabilitation showed significantly greater improvements on a cognitive battery over 3 months than those who received vocational rehabilitation alone, and had better work outcomes over the 2-year follow-up [15].

From this point of view, our study supports what is already known about the interaction between motivation, encouragement of cognitive abilities and performance improvement [16]. When compared with users receiving a rehabilitation program or a more traditional vocational training program, the project produced the added value of an improvement in the specific dimension of the impairment of the HoNOS scale. This could then be the effect of a greater motivation due to the fact that one learns a job that can be performed on the market.

The fact that the project has stimulated many expectations related to the most important needs of the real economy of the area, and that the people suffering from mental illnesses have been the focus of this process, has also produced a strong anti-stigma background. The context of vocational training was therefore particularly favourable, which is one of the elements that justify the positive result.

From another point of view although the improvement of patients participating in the work inclusion program was not much greater than the one achieved with conventional rehabilitation, the chances of patients' finding a job on the labour market may be better since they learnt something there is demand for.

\section{Limitations}

This study is limited by the small size of the experimental sample, its non-randomized design, the use of a simple instrument that may be more suitable to monitor daily routines than for a research project, and the fact that the raters were not blind to the status of the patients. Another limitation is the relatively brief observation period (three months).

This study should be regarded as preliminary and its results require confirmation.

The hypothesis that the best result achieved by the experimental cohort of patients may be due to the positive effects of the project on the social needs of an entire area, is purely heuristic. This hypothesis is useful to stimulate new types of research and cannot be regarded as final, given the complexity of factors that interact in such a project and the methodological limitations of this study.

However if this innovative approach is confirmed by future studies, it could become a model for anti-stigma actions and work inclusion projects especially, but not limited to, in times of economic crisis.

\section{CONFLICT OF INTEREST}

The authors confirm that this article content has no conflicts of interest.

\section{ACKNOWLEDGEMENTS}

Declared none. 


\section{REFERENCES}

[1] Carta MG, Agaj A, Harapej E, et al. Outcomes of discharged females versus those waiting for discharge from Vlore Psychiatric Hospital (Albania). Int J Soc Psychiatry 2013; 59(7): 682-9

[2] Schnabel P. Protecting and including vulnerable people in times of economic crisis, in Mental health and well-being at the workplace protection and inclusion in challenging Times. In: Baumann A, Muijen M, Eds. World Health Organization, Copenaghen 2010

[3] Carta MG, Sancassiani F, Tuligi F, et al. A one year follow-up study on patients with severe mental disorders of Sardinian Public Mental Health Services after two opposite changes in the regional policies. BMC Psychiatry (submitted).

[4] Wing J, Curtis RH, Beevor AS, Park BG, Hadden S, Burns A. Health of the NationOutcomeScales (HoNOS). Research and development. Br J Psychiatry 1998; 172: 11-8.

[5] Royal College of Psychiatrist (2011). www.rcpsych.ac.uk/training/honos/references.aspx

[6] Silverstein SM, Bellack AS. A scientific agenda for the concept of recovery as it applies to schizophrenia. Clin Psychol Rev 2008; 28:1108-24.

[7] Nordén T, Malm U, Norlander T. Resource Group Assertive Community Treatment (RACT) as a tool of empowerment for clients with severe mental illness: a meta-analysis. Clin Pract Epidemiol Ment Health 2012; 8: 144-51.
[8] Miyamoto Y, Sono T. Lessons from peer support among individuals with mental health difficulties: a review of the literature. Clin Pract Epidemiol Ment Health 2012; 8: 22-9.

[9] Ramon S, Healy B, Renouf N. Recovery from mental illness as an emergent concept and practice in Australia and the UK. Int J Soc Psychiatry 2007; 53 (2): 108-22

[10] Sells DJ, Stayner DA, Davidson L. Recovering the self in schizophrenia: an integrative review of qualitative studies. Psychiatr Q 2004; 75(1): 87-97.

[11] Dunn EC, Wewiorski NJ, Rogers ES. The meaning and importance of employment to people in recovery from serious mental illness: results of a qualitative strudy. Psychiatr Rehabil J 2008; 32: 59-62

[12] Flammer E, Steinert T, Eisele F, Bergk J, Uhlmann C. Who is Subjected to Coercive Measures as a Psychiatric Inpatient? A Multi-Level Analysis. Clin Pract Epidemiol Ment Health 2013; 9 : $110-9$.

[13] Spanoil L, Wewiorski NJ, Gagne C, Anthony WA. The process of recovery from schizophrenia. Int Rev Psychiatry 2002; 14: 327-36.

[14] Bio DS, Gattaz WF. Vocational rehabilitation improves cognition and negative symptoms in schizophrenia. Schizophr Res 2011; 126(1-3): 265-9.

[15] McGurk SR, Mueser KT, DeRosa TJ, Wolfe R. Work, recovery, and comorbidity in schizophrenia: a randomized controlled trial of cognitive remediation. Schizophr Bull 2009; 35(2): 319-35.

[16] Mura G, Petretto DR, Bhat KM, Carta MG. Schizophrenia: from epidemiology to rehabilitation. Clin Pract Epidemiol Ment Health 2012; 8: 52-66

Received: October 17, 2013

Revised: October 23,2013

Accepted: October 23, 2013

(C) Carta et al.; Licensee Bentham Open.

This is an open access article licensed under the terms of the Creative Commons Attribution Non-Commercial License (http://creativecommons.org/licenses/by-nc/3.0/) which permits unrestricted, non-commercial use, distribution and reproduction in any medium, provided the work is properly cited. 